DOI: https://doi.org/10.24867/04AM01Ristic

\title{
TRIBODIJAGNOSTIKA STATIČKOG KOEFICIJENTA TRENJA PO PRINCIPU KOSE RAVNI
}

\section{TRIBODIAGNOSTICS OF THE STATIC FRICTION COEFFICIENT BY PRINCIPLE OF INCLINED PLANE}

\author{
Lazar Ristić, Đorđe Vukelić, Fakultet tehničkih nauka, Novi Sad
}

\begin{abstract}
Oblast - PROIZVODNO MAŠINSTVO
Kratak sadržaj - U radu su prezentovani rezultati merenja statičkog koeficijenta trenja po principu kose ravni. Eksperimentalna istraživanja su sprovedena za kontaktne parove napravljene od različitih materijala. Dobijeni rezultati ukazuju da kontaktne parove čiji su elementi napravljeni od čelika, sivog liva $i$ mesinga karakterišu niže vrednosti statičkog koeficijenta trenja. Gumu kao materijal kontaktnog para karakterišu visoke vrednosti statičkog koeficijenta trenja. Na kraju su dati odgovarajući zaključci i pravci budućih istraživanja.
\end{abstract}

Ključne reči: Tribometar, statički koeficijent trenja

\begin{abstract}
The results of the measurement of the static friction coefficient on the principle of inclined plane are presented. Experimental investigations were carried out for contact pairs made of different materials. The obtained results indicate that contact pairs whose elements are made of steel, cast iron and brass are characterized by lower values of the static friction coefficient. The rubber as a contact-pair material is characterized by high values of the static friction coefficient. At the end, appropriate conclusions and future directions research are given.
\end{abstract}

Keywords: Tribometer, static friction coefficient

\section{UVOD}

Tribologija je jedna od tehničkih disciplina čiji razvoj ima izuzetan uticaj na pouzdanost i vek mašinskih sistema. Tribološka istraživanja i korišćenje već ostvarenih znanja, kako u procesu konstruisanja tako i u proizvodnji i eksploataciji, predstavljaju neophodnost savremene industrije kada se posmatraju njeni današnji zahtevi za ekonomično korišćenje materijala, racionalno trošenje energije, povećanje pouzdanosti mašinskih sistema i smanjenje troškova održavanja. Tribologija je naučnotehnička disciplina koja obuhvata istraživanja procesa trenja, habanja i podmazivanja, kao i postupaka za smanjenje i optimizaciju ovih procesa kod različitih mašinskih sistema [1].

Trenje se definiše kao sila koja deluje između površina kontakta dva tela suprotstavljajući se njihovom relativnom kretanju.

\section{NAPOMENA:}

Ovaj rad proistekao je iz master rada čiji mentor je bio dr Đorđe Vukelić, vanr. prof.
Trenje je složena pojava koja zavisi od velikog broja faktora kontaktnih površina, kao što su: materijal, geometrija, brzina klizanja (kotrljanja), normalno opterećenje i dr. [2].

Sila trenja je proporcionalna normalnoj sili koja deluje na površine koje su u kontaktu, što se može prikazati sledećim izrazom [3]:

$$
\mathrm{F}_{\mathrm{t}}=\mu \cdot \mathrm{F}_{\mathrm{n}}
$$

gde je: $F_{t}$ sila trenja, $\mu$ koeficijent trenja a $F_{n}$ normalna sila. Veličina sile trenja ne zavisi od veličine kontaktne površine i ravnomerno je raspoređena po njoj. Sila trenja deluje tangencijalno u odnosu na kontaktnu površini i ima smer dejstva suprotan smeru tendencije kretanja.

Prema stanju kretanja tela, trenje se deli na [4]:

- trenje mirovanja (statičko trenje) - otpor koji se javlja na dodirnim površinama dva tela koja miruju,

- trenje kretanja (kinematsko trenje) - otpor koji se javlja na dodirnim površinama dva tela koja se kreću.

U stanju mirovanja sila trenja je na mestima kontakta površina veća ili jednaka sa rezultantom tangencijalnih sila koja izaziva kretanje. Trenje postoji na površini kontakta čvrstih tela $i$ kada su tela $u$ relativnom mirovanju, jer je potrebno uložiti znatnu silu da bi se izazvalo početno relativno kretanje. Nakon neke granične vrednosti sile telo se pokreće. Sila trenja potom raste do neke maksimalne vrednosti statičke sile trenja. Nakon toga javlja se relativno kretanje između tela a sila trenja postaje kinematska sila trenja, a njena vrednost je nešto manja od statičke sile trenja. Pri tome, dok tela miruju koeficijent trenja ima jednu vrednost a tokom kretanja drugu vrednosti. Vrednosti koeficijenta trenja tokom kretanja su manje nego tokom mirovanja u identičnim uslovima ostvarivanja kontakta $[5,6]$.

$\mathrm{U}$ realnim industrijskim sistemima vrlo je teško, a u većini slučajeva i nemoguće, kvantitativno odrediti veličinu koeficijenta trenja. Merenje sile trenja i normalnog opterećenja, odnosno određivanje koeficijenta trenja vrši se na posebnim mernim uređajima tribometrima.

\section{METODOLOGIJA}

Merenje statičkog koeficijenta trenja je moguće izvesti na različite načine, a jedan od njih je princip kose ravni (slika 1) koji se zasniva na gravitacionoj sili [7,8]. Na slici je prestavljeno telo mase $(\mathrm{m})$ koje se nalazi u stanju statičke ravnoteže. Telo se nalazi na kosoj ravni koja je nagnuta u odnosu na horizontalu za određeni ugao $(\alpha)$. Na 
telo deluje gravitaciona sila $(\mathrm{Q}=\mathrm{m} \cdot \mathrm{g}) \mathrm{u}$ vertikalnom pravcu, sila trenja $\left(\mathrm{F}_{\mathrm{t}}\right)$ u pravcu kose ravni i normalna reakcija podloge $\left(F_{n}\right)$ upravno na pravac kose ravni.

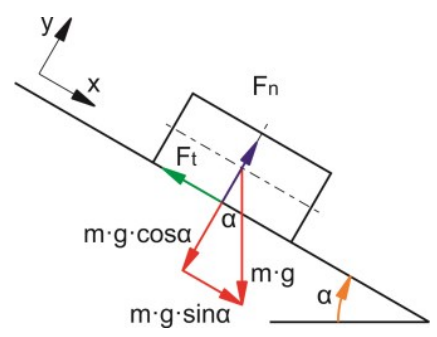

Slika 1. Raspored sila

Statički koeficijent trenja, po definiciji, jednak je:

$$
\mu=F_{t} / F_{n}
$$

$\mathrm{Na}$ osnovu statičkih uslova ravnoteže za x i $y$ osu (slika 1) sledi da je:

$$
\begin{aligned}
& F_{t}=m \cdot g \cdot \sin \alpha \\
& F_{n}=\mathrm{m} \cdot g \cdot \cos \alpha
\end{aligned}
$$

Zamenom izraza (3) i (4) u (2) dobija se izraz za izračunavanje statičkog koeficijenta trenja kontaktnog para:

$$
\begin{gathered}
\mu=\mathrm{m} \cdot \mathrm{g} \cdot \sin \alpha / \mathrm{m} \cdot \mathrm{g} \cdot \cos \alpha \\
\mu=\sin \alpha / \cos \alpha \\
\mu=\operatorname{tg} \alpha
\end{gathered}
$$

$\mathrm{Na}$ osnovu izraza (7) moguće je izračunati statički koeficijent trenja ako se predhodno izmeri ugao nagiba kose ravni $(\alpha)$ pri kojoj dolazi do pokretanja jednog elementa kontaktnog para u odnosu na drugi.

Tribometar upotrebljen u eksperimentalnim istraživanjima koji funkcioniše na principu kose ravni prikazan je na slici 2. Sklop tribometra sastavljen je iz funkcionalnih celina koji omogućavaju ostvarivanje potrebnog zakretanja kose ravni jednog elementa kontaktnog para $\mathrm{u}$ odnosu na drugi.

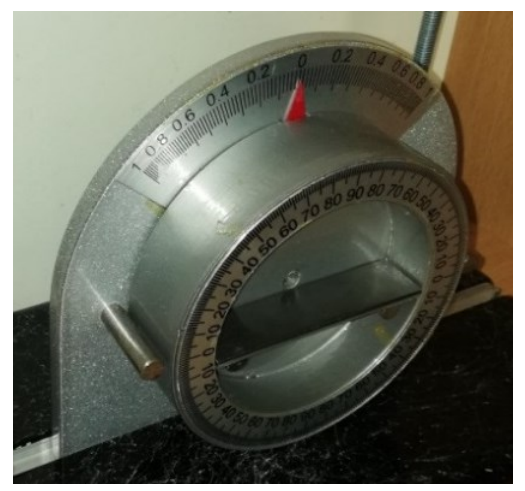

Slika 2. Tribometar

Pre izvođenja postupka merenja potrebno je izvršiti nivelaciju uređaja i dovođenje kose ravni u početni (horizontalni) položaj zakretanjem diska.

$\mathrm{Na}$ taj način se obezbeđuje zauzimanje horizontalnog položaja prvog elementa kontaktnog para. Nakon izvršene pripreme postavlja se prvi element kontaktnog para tako da nalegne na čivije i jednu stranu udubljenja na disku. Potom se na njega postavlja drugi element. Time je formiran kontaktni par (slika 3).

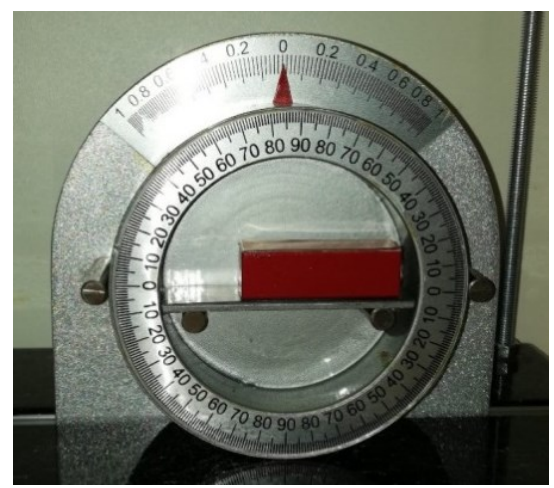

Slika 3. Kontaktni par

Nakon formiranja kontaktnog par vrši se zakretanje diska a istovremeno sa njim i zakretanje kose ravni (slika 4). Poželjno je da se zakretanje vrši što manjom brzinom. kako bi se povećala tačnost merenja. Posle svakog zakretanja, od približno $0,5^{\circ}$, pravi se kratka pauza, i posmatra se da li drugi element kontaktnog para miruje ili je započelo njegovo kretanje. U trenutku kada se uoči početak kretanja, drugog elementa kontaktnog para $\mathrm{u}$ odnosu na prvi element, vrši se očitavanje ugla zakretanja kose ravni - $\alpha$.

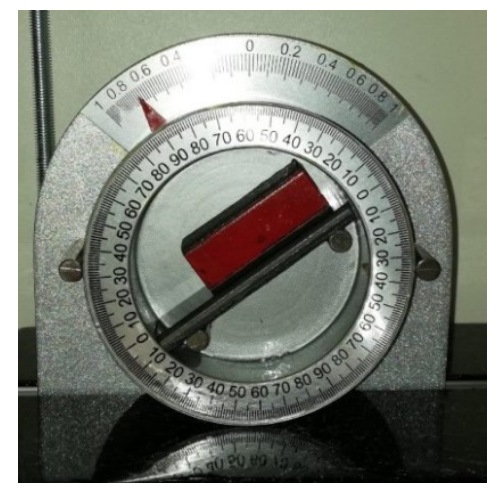

Slika 4. Zakretanje kose ravni

\section{REZULTATI}

Elementi kontaktnih parova na kojima su izvršena eksperimentalna istraživanja napravljeni su od sledećih materijala: čelik (S235JR), sivi liv (SL25), mesing (MS58) i silikonska guma.

Merenje ugla nagiba kose ravni izvršeno je za 10 kombinacija materijala kontaktnih parova, i to:

- $\quad$ kontaktni par "čelik - čelik",

- $\quad$ kontaktni par "sivi liv - sivi liv",

- $\quad$ kontaktni par "mesing - mesing",

- $\quad$ kontaktni par "guma - guma",

- $\quad$ kontaktni par "čelik - sivi liv",

- $\quad$ kontaktni par "čelik - mesing",

- $\quad$ kontaktni par "čelik - guma",

- $\quad$ kontaktni par "sivi liv - mesing",

- $\quad$ kontaktni par "sivi liv - guma",

- $\quad$ kontaktni par "mesing - guma". 
Za svaki kontaktni par izvršeno je po 30 merenja ugla nagiba kose ravni. Izmerenje vrednosti ugla nagiba kose ravni su prikazane na slici 5 .

$\mathrm{Na}$ osnovu izmerenih vrednosti ugla nagiba kose ravni izračunate su vrednosti statičkog koeficijenta trenja za pojedine kontaktne parove (slika 6).
U tabeli 1 prikazane su srednje aritmetiče vrednosti statičkog koeficijenta trenja, njegove minimalne i maksimalne vrednosti, kao i standardne devijacije za pojedine kontaktne parove.

$\mathrm{Na}$ slici 7 su prikazane srednje aritmetičke vrednosti statičkog koeficijenta trenja za sve kontaktne parove.

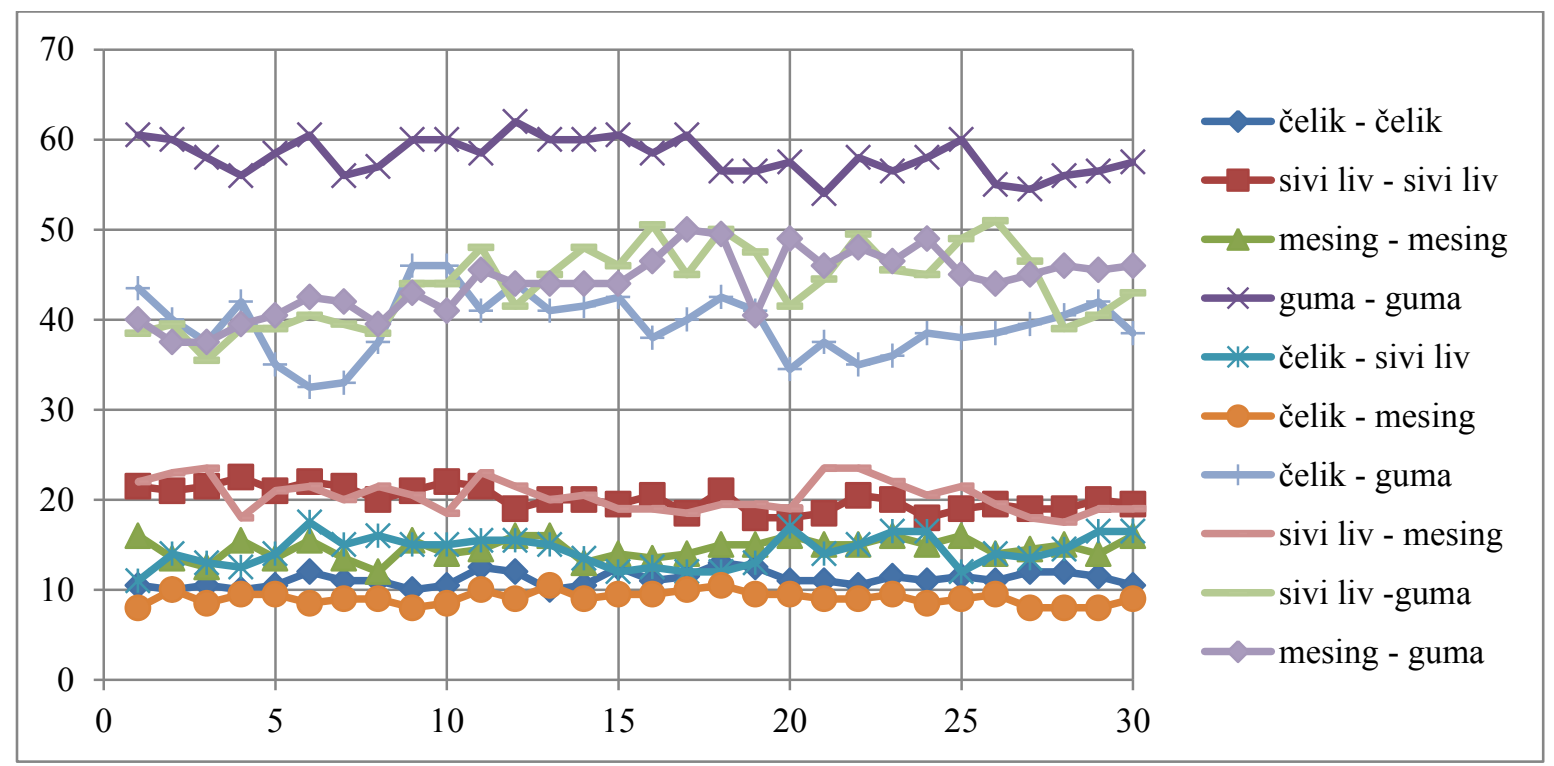

Slika 5. Izmerene vrednosti ugla nagiba kose ravni

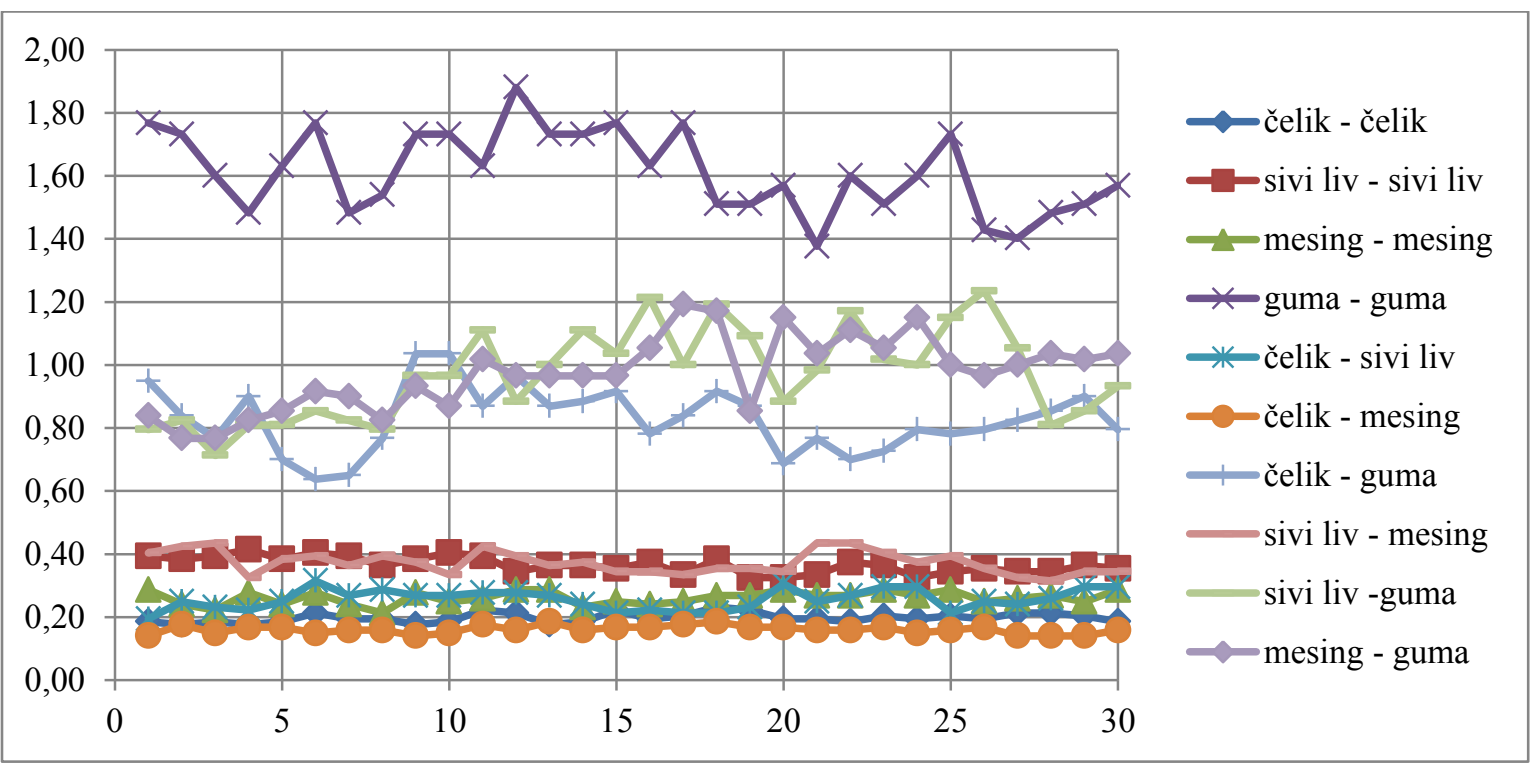

Slika 6. Izračunate vrednosti statičkog koficijenta trenja klizanja

Tabela 1. Statistički parametri

\begin{tabular}{|c|c|c|c|c|c|c|c|c|c|c|}
\hline \multirow{2}{*}{ Parametar } & \multicolumn{10}{|c|}{ Kontakti par } \\
\cline { 2 - 12 } & $\begin{array}{c}\text { čelik } \\
\text { čelik }\end{array}$ & $\begin{array}{c}\text { sivi liv } \\
\text { sivi liv }\end{array}$ & $\begin{array}{c}\text { mesing } \\
\text { mesing }\end{array}$ & $\begin{array}{c}\text { guma } \\
\text { guma }\end{array}$ & $\begin{array}{c}\text { čelik } \\
\text { sivi liv }\end{array}$ & $\begin{array}{c}\text { čelik } \\
\text { mesing }\end{array}$ & $\begin{array}{c}\text { čelik } \\
\text { guma }\end{array}$ & $\begin{array}{c}\text { sivi liv } \\
\text { mesing }\end{array}$ & $\begin{array}{c}\text { sivi liv } \\
\text { guma }\end{array}$ & $\begin{array}{c}\text { mesing } \\
\text { guma }\end{array}$ \\
\hline $\bar{\mu}$ & 0,20 & 0,37 & 0,26 & 1,61 & 0,26 & 0,16 & 0,83 & 0,37 & 0,97 & 0,97 \\
\hline$\mu_{\min }$ & 0,18 & 0,32 & 0,21 & 1,38 & 0,19 & 0,14 & 0,64 & 0,32 & 0,71 & 0,77 \\
\hline$\mu_{\max }$ & 0,23 & 0,41 & 0,29 & 1,88 & 0,32 & 0,19 & 1,04 & 0,43 & 1,23 & 1,19 \\
\hline$\sigma_{\mu}$ & 0,02 & 0,03 & 0,02 & 0,13 & 0,03 & 0,01 & 0,10 & 0,04 & 0,15 & 0,12 \\
\hline
\end{tabular}




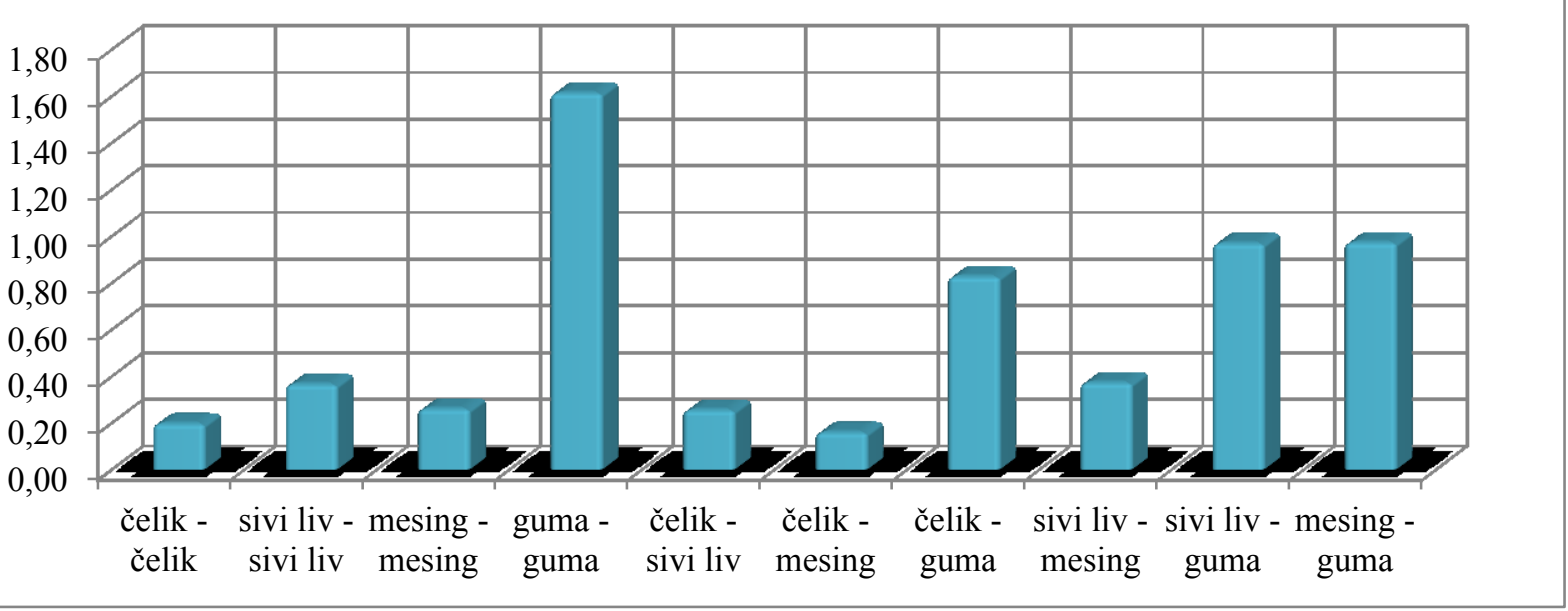

Slika 7. Srednje aritmetičke vrednosti statičkog koeficijenta trenja

$\mathrm{Na}$ bazi prikazanih rezultata može se konstatovati da su najveće vrednosti statičkog koeficijenta trenja klizanja dobijene za kontaktni par guma-guma, a najmanje vrednosti statičkog koeficijenta trenja za kontaktni par čelik-mesing.

Guma pokazuje izuzetno dobre tribološke karakteristike u smislu ostvarivanja izuzetno visokih vrednosti koeficijenta trenja. Srednje aitmetičke vrednosti statičkog koeficijenta trenja kontaktnih parova gde je jedan od elemenata od gume se kreću u rasponu od 0,83 do 0,97. To znači da je sila trenja veoma velika, tj. bliska normalnoj sili. S obzirom na to, preporučuje se upotreba elemenata od gume u slučajevima kada je potrebno ostvariti visoke koeficijente trenja. To se može postići „oslojavanjem“ elemenata u kontaktu sa gumom ili umetanjem podemtača i podloški napravljenim od gume između dva elementa. U slučaju da je potrebno obezbediti niske vrednosti koeficijenta trenja gumu kao materijal kontaktnog elementa ne treba upotrebljavati.

Niže vrednosti statičkog koeficijenta trenja se dobijaju za sve kontaktne parove u kojima ni jedan od elemenata nije napravljen od gume. U ovom slučaju srednje aritmetičke vrednosti statičkog koeficijenta trenja se kreću u rasponu od 0,16 do 0,37 . Posebno niske vrednosti kinematskog koeficijenta trenja karakterišu kontaktno par čelik-mesing i kontaktni par čelik-čelik.

\section{ZAKLJUČCI}

$\mathrm{U}$ većini slučajeva, u različitim pokretnim elementima mašina, uređaja i postrojenja, trenje je nepoželjna i štetna pojava. Na savlađivanje sile trenja kao otpora kretanja bilo koje vrste, troši se znatna količina mehaničke energije. Kao posledica trenja na površinama u kontaktu dolazi do trošenja i zagrevanja materijala površina. Rezultati eksperimentalnih istraživanja ukazu, da u ovim slučajevima, kada je funkcija cilja optimizacije tribomehaničkog sistema minimum trenja, kao elemente kontaktnog para treba upotrebljavati elemente od čelika, sivog liva i mesinga.

Međutim, trenje u nekim slučajevima može biti korisna fizička pojava. Stoga, ako je funkcija cilja optimalizacije tribomehaničkog sistema maksimum trenja kao jedan od kontaktnih elemenata treba upotrebljavati gumu. Gumu karakteriše odlična rastegljivost i fleksibilnost. Velike vrednosti statičkog koeficijenta trenja su posledica toga što guma može da podnese veće elastične deformacije od većine drugih materijala i da se vrati u početno stanje bez permanentne deformacije.

Buduća istraživanja biće usmerena na merenja statičkog koeficijentra trenja kontaktnih elemenata napravljenih od drugih materijala sa različitim karakteristikama.

\section{LITERATURA}

[1] A. Rac, Osnovi tribologije, Mašinski fakultet, Beograd, 1991.

[2] B. Ivković, A. Rac, Tribologija, Jugoslovensko društvo za tribologiju, Kragujevac, 1995.

[3] J. P. Blau, „The significance and use of the friction coefficient", Tribology International, Vol. 34, pp. 585-91, 2001.

[4] A. Devaraju, A review on important factors affecting dry sliding friction, Journal of Surface Science and Technology, Vol. 32, No. 3-4, pp. 73-78, 2016.

[5] I. M. Hutchings, Leonardo da Vinci's studies of friction, Wear, Vol. 360-361, pp. 51-66, 2016.

[6] K. Kato, Wear in relation to friction - A review, Wear, Vol. 241, No. 2, pp. 151-157, 2000.

[7] ASTM G219-18: Standard Guide for Determination of Static Coefficient of Friction of Test Couples Using an Inclined Plane Testing Device, ASTM International, 2018.

[8] ASTM G115-10: Standard Guide for Measuring and Reporting Friction Coefficients, ASTM International, 2010 .

\section{Kratka biografija:}

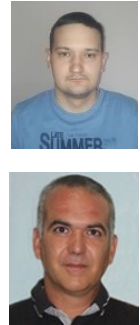

Lazar Ristić rođen je u Novom Sadu 1993. god. Master rad na Fakultetu tehničkih nauka iz oblasti Mašinskog inženjerstva odbranio je 2019.god. kontakt: laleristic.rs@gmail.com@gmail.com

Đorđe Vukelić rođen je u Novom Sadu 1974. godine. Doktorirao je na Fakultetu tehničkih nauka 2010. god., a od 2015 je zvanju vanrednog profesora. 